A autora problematiza a tese freudiana segundo a qual o funcionamento psíquico e pulsional apoia -se sobre a experiência de satisfação das necessidades vitais do organismo, e em especial a fome. Segundo ela, aquilo que é alucinado pelo bebê no polo alucinatório desta experiência de satisfação é antes de tudo a voz materna, e mais especialmente seus picos prosódicos, que devem ser tomados como primeiros objetos da pulsão oral. Psicanálise de bebês pulsão oral - voz materna

THE VOICE AS THE FIRST OBJECT OF THE ORAL DRIVE

The author discusses the freudian thesis of the anaclisis of the psychic functions of the vital needs. She sustains that the first objects of the oral drive are not those related to the hunger, but the prosodic peaks of the maternal voice.

Babies psychoanalysis; oral drive; maternal voice.

\section{A VOZ COMO PRIMEIRO OBJETO DA PULSÃO ORAL}

$\prod$ Marie-Christine Laznik objeto da pulsão oral", mas, após ter trabalhado com algumas pesquisas psicolingüísticas atuais, eu deveria propor "Os picos prosódicos como primeiros objetos da pulsão oral”.

Freud, no final de sua vida, dizia na "Introdução...” (1938): “O primeiro órgão que se manifesta enquanto zona erógena e que emite para o psiquismo uma reivindicação libidinal, é, desde o nascimento, a boca. Qualquer atividade psíquica é agenciada para proporcionar satisfação às necessidades dessa zona. Trata-se evidentemente em primeiro lugar de agir para a autoconservação pela alimentação. Todavia, cuidemos de não confundir fisiologia e psicologia. Muito cedo, a criança, sugando obstinadamente, mostra que existe uma necessidade de satisfação que, ainda que extraia sua origem da alimentação e seja excitada por ela, procura seu ganho de prazer, independentemente desta. Assim, esta necessidade pode e deve ser qualificada como sexual". Referindo-nos ao texto sobre a pulsão (1915), podemos acrescentar: "pulsional”.

Freud insistia em partir do orgânico, e portanto apoiou sua "psicologia científica" - como ele a denomina no Projeto (Freud, 1895) - sobre o

Psicanalista. Membro da Associação Freudiana Internacional. 
estudo do organismo. Lembremo-nos, por exemplo, da importância da noção de desamparo do pequeno homem (Hilflosigkeit) na sua elaboração da experiência alucinatória de satisfação.

Há doze anos havíamos organizado jornadas sobre Melanie Klein em nossa sociedade lacaniana. Confesso que me pareceu estranho ouvir alguns de meus colegas, da primeira geração de lacanianos, dizer - a respeito justamente deste pólo alucinatório de satisfação do desejo - que aquilo que era alucinado pelo bebê na experiência de satisfação era a voz materna. Para afirmá-lo, esses colegas apoiavam-se na experiência das psicoses adultas em que, efetivamente, os primeiros fenômenos elementares alucinatórios que aparecem são acústicos. Devo reconhecer que a idéia de que aquilo que poderia ser registrado no pólo alucinatório de satisfação, no nível dos traços mnêmicos das representações de desejo (Wunschvorstellungen), seriam sons, ou traços prosódicos, parecia-me impertinente. Para mim havia aí mais os traços mnêmicos das satisfações das necessidades primeiras de fome e de sede. Freud (1905) havia dito: "Quando vemos uma criança satisfeita largar o seio deixando-se inclinar para trás e adormecer, com as faces rosadas, um sorriso feliz, não podemos nos impedir de dizer que esta imagem permanece como o protótipo da expressão da satisfação sexual na existência ulterior". Eu permanecia portanto muito ligada a uma concepção clássica do apoio do funcionamento psíquico e pulsional sobre a experiência de satisfação das necessidades vitais do organismo.
Mais tarde, trabalhando atentamente o "Projeto"1, compreendi que Freud pensava que no pólo alucinatório de satisfação estão inscritos os traços mnêmicos e os atributos desse próximo assegurador (Nebenmensch), aquele que está atento às necessidades do recém-nascido e também uma parte recolhida, que permanece como uma coisa (das Ding), e ele acrescentava: "Seriam, por exemplo, no nível visual $^{2}$, os traços". Pareceu-me possível associar isto ao olhar fundador da mãe (Laznik, 1995) - ou dos pais - e ao que Winnicott chama o "rosto da mãe como espelho". Algo do desejo da mãe sobre a criança seria traduzido pelos traços de seu rosto, no modo de olhá-lo; isto também estava registrado no pólo alucinatório de satisfação. Hoje, permito-me dizer que esses traços são também acústicos e que têm seu eixo nos modos prosódicos da palavra dos pais a seu bebê. Foram os trabalhos dos psicolingüistas, bem como certos casos clínicos, que me possibilitaram esta formulação.

\section{OBSERVAÇÕES CLÍNICAS}

E no Centro Alfred Binet, em nosso grupo de pesquisa sobre os bebês, graças às leituras que nos foram apresentadas por Marie-Françoise Bresson, que minha atenção é atraída pelos trabalhos dos psicolingüistas. As pesquisas dos psicolingüistas, resumidas para o grande público em 1977 por Benédicte de Boysson Bar- 
dies (1996) e, dez anos antes, por Mehler et Dupoux (1990), e os trabalhos de Mme. Busnel sobre as competências acústicas de fetos, questionam muito nossos hábitos de pensamento. Caminhando então de surpresa em surpresa, fui obrigada a me dizer que o bebê de Freud - como eu o representava para mim - estava sendo seriamente reconsiderado. Mas o bebê de Lacan também carecia de remanejamentos. Lacan chama o sujeito humano o "falasser", pois ele se encontra, de imediato, na linguagem. Certamente. Mas como isto se passa com o infans, ou seja, com aquele que ainda não fala? Como isso acontece no plano clínico? Lacan falou muito do desejo do Outro, mas não dispunha de uma clínica de bebês que lhe possibilitasse articular suas hipóteses no plano fenomenológico ${ }^{3}$. Além disso, Lacan fica muito preso ao "Projeto". Para ele, a primeira manifestação do bebê é um grito, isto é, uma descarga motora que acontece porque a fome ou a sede estão na origem de uma excitação interna.

Já no início de seu livro, Mme. de Boysson-Bardies lembra que o bebê identifica a voz da mãe antes mesmo da primeira mamada, portanto, antes que qualquer leite possa acalmar qualquer necessidade ${ }^{4}$.

Recentemente acompanhei, em minha família mais próxima, com o nascimento de um bebê, uma pequena Alice. Na maternidade não lhe deram mamadeira, aguardando a descida do leite de sua mãe. Esta dizia a seu bebê que havia recebido apenas colostro, e Alice, bebendo as palavras de sua mãe, acalmava-se e escutava. Ela acompanhava, completamente interessada, os movimentos da boca da mãe.

Essa observação clínica, do mesmo modo que as pesquisas dos psicolingüistas não apontam na direção das afirmações de Spitz sobre a passagem necessária pela experiência de satisfação da necessidade alimentar para a constituição do aparelho psíquico. Spitz (1962) havia se apoiado sobre um caso clínico aparentemente incontestável. Em 1957, ele estuda um dos primeiros casos de criança alimentada diretamente no estômago, a pequena Monica, que, pela sua descrição, estava num estado de marasmo semelhante ao hospitalismo. Spitz conclui que, se não há experiência de procura, experiência de satisfação alimentar pela boca, a negação, isto é, os movimentos cefalógiros negativos da negação não podem se estabelecer. Para Spitz, qualquer atividade psíquica criadora - autogeração de formas que conduza aos processos de pensamento - é iniciada pela experiência sensorial ligada à situação de alimentação. Se esta atividade psíquica não se estabelece, haverá conseqüências danosas no plano simbólico. Ginette Raimbault (1980, pp.5-84), numa pesquisa terminada em 1979 sobre as crianças em reanimação digestiva, 
havia encontrado a confirmação da teoria do apoio na satisfação da necessidade. Estes primeiros bebês, salvos assim pela medicina de morte certa, apresentavam todos os atrasos psicomotores, relacionais e da linguagem que se prolongaram até os 6 anos. Estes resultados pareciam confirmar as hipóteses de Spitz.

No consultório de bebês e pais do Centro Alfred Binet, recebemos um bebê de 11 meses, que vou chamar de Marianne. Em função de uma má-formação fetal digestiva grave ${ }^{5}$, ela foi inicialmente alimentada por cateter, depois ${ }^{6}$ por sonda, não tendo portanto nunca tido a experiência de satisfação da necessidade alimentar pela boca.

No início Marianne se apresenta como um bebê triste, com pais tensos, crispados sobre seu fracasso em alimentá-la de modo natural. Mas, no trabalho terapêutico, ela vai, muito rapidamente, mostrar-se viva, capaz de comer as histórias que lhe contamos, de beber as palavras de uns e de outros. Ela apresenta boas representações de mãe amamentadora, mostra um auto-erotismo oral, dá provas de uma organização da simbolização, e, muito rapidamente, ela fala.

Se isso é possível tão rapidamente, é porque Marianne não foi alimentada apenas artificialmente; ela havia recebido também de seus pais, já no hospital, palavras alimentadoras ${ }^{7}$.

Quando brinco de me deixar alimentar, Marianne repete, em espelho, o prazer que se pode ter em ser alimentado, o que significa que ela apresenta algo que the é desconhecido no plano alimentar. Em outro jogo, é ela que vai se oferecer como objeto delicioso, "boa de morder", e eis que ela descobre a cavidade bucal de seus pais, e depois a sua própria. É todo o circuito da pulsão oral, em seus diversos tempos sucessivos, que nela se estabelece.

Numa sessão recente, a organização simbólica aparece nitidamente: Marianne tem 14 meses, e seu pai viajou. Ela coloca uma boneca atrás de uma cadeira, faz com que ela desapareça notificando-me disso, e, quando eu lhe digo "sim, papai não está, é como a boneca que não está", ela responde: "lá, lá", representação de um "fora". Ela vai então buscar o telefone e, dizendo "não, papai", aponta a porta, lugar da saída, do fora. Estamos portanto diante de alguém que, não tendo sido jamais alimentada pela boca, não apresenta, entretanto, nenhum atraso na organização simbólica ou da linguagem.

Por ocasião de um de nossos seminários mensais, como discutíamos esse caso ${ }^{8}$, foi-me dito que porque Marianne nunca tinha sofrido fome, ela teria feito uma espécie de experiência de satisfação da necessidade e que talvez por isso todo o resto se seguisse. O problema é mais complicado. Se pensamos no bebê de Spitz, 
ou naqueles descritos por Ginette Raimbault, não podemos dizer que se Marianne tem um bom desenvolvimento simbólico é porque ao ser alimentada teve a experiência de satisfação da necessidade. Todas as crianças citadas anteriormente foram alimentadas, o que não as impediu de conhecer um destino pulsional muito mais obstruído.

Eu teria talvez pensado num destino excepcional para Marianne se eu não tivesse conhecido o trabalho de Annie Mercier (1995). Ela descreve bebês alimentados artificialmente num serviço parisiense de pediatria geral. E muito provável que certo número de observações feitas por Ginette Raimbault já tivesse sido levado em conta ${ }^{9}$, particularmente as que visavam facilitar, desde o início, o laço dos pais ao bebê. Podemos supô-lo, pois a evolução dos bebês desse serviço, como descreveu Annie Mercier, com freqüência foi semelhante à que pudemos constatar com Marianne. O que obriga a autora a dizer que essa clínica reconsidera algumas hipóteses comumente admitidas sobre a teoria do apoio. No âmbito de uma tese de mestrado, ela não se permite ir até o fim do que apresenta aqui um problema. Annie Mercier contenta-se em pensar, como eu mesma fiz num primeiro tempo a respeito de Marianne, que "cada uma dessas crianças demonstrou competências excepcionais" 10 .

E se aí não se tratasse de exceção? Deveríamos dizer então que os bebês portadores dessas patologias alimentares radicais nos ensinam que, se as necessidades vitais são apaziguadas, o bebê emprega suas competên- 
cias na busca de um outro objeto diferente daquele da satisfação da necessidade vital.

Vamos levantar algumas questões teóricas sobre as conseqüências desses dados clínicos. Freud era um homem curioso sobre as pesquisas de seu tempo, e acredito que, diante de dados desse gênero, ele seria o primeiro a tirar conclusões em relação a sua teoria. Talvez essas lhe permitissem articular melhor algumas dificuldades de alguns de seus conceitos.

\section{ALGUMAS REFLEXÕES TEÓRICAS}

Um dos problemas na obra de Freud é o reequilíbrio permanente que ele deve garantir entre a teoria do apoio e uma de suas concepções do auto-erotismo. Ele estava dividido entre esses dois pontos opostos. Talvez as pesquisas atuais lhe possibilitassem resolver esse impasse. Tentemos, primeiramente, formulá-lo bem:

a) $\mathrm{O}$ conceito de apoio

"O seio amamentador da mãe é para a criança o primeiro objeto erótico, o amor aparece embasando-se na satisfação da necessidade de alimento" (Freud, 1938).

O apoio possibilita a Freud estabelecer uma representação teórica do aparelho psíquico que supõe uma historicidade - o que é muito importante - e um laço com um Outro primordial que ele chama de próximo assegurador (Nebenmensch), aquele que vai dar a resposta específica capaz de apaziguar as necessidades (de fome, de sede, bem entendido). Segue-se uma queda da tensão interna para o bebê, vivida como experiência de satisfação, que irá inscrever-se no pólo alucinatório de satisfação. Mais tarde, quando é deixado sozinho, o bebê poderá reevocar os traços mnêmicos dessa experiência de satisfação ${ }^{11}$, bem como os traços deste Outro atento, e reencontrar um apaziguamento; é a experiência alucinatória primária. É nesses termos que Freud (1973) descreve, no "Projeto", a constituição do aparelho psíquico.

A partir daí podemos pensar um auto-erotismo, sucedâneo da experiência alucinatória primária, misturado a certos traços desse Outro assegurador. Esta concepção visa integrar o auto-erotismo na historicidade da relação com o Outro ${ }^{12}$. Mas esta atrapalha Freud, e é compreensível, na medida em que faz qualquer experiência psíquica derivar do registro fisiológico.

Como não confundir fisiologia e psicologia, pergunta-se ele? Como separar as pulsões, sexuais por excelência, do registro da 
conservação do organismo? A esta questão central, Freud responderá introduzindo a idéia de um auto-erotismo inato, que com a aparência de solução irá criar novos problemas teóricos.

b) A hipótese de um auto-erotismo inato

A língua alemã possui duas palavras diferentes para o "verbetéter", conforme a referência a alimentar-se, beber ou sugar, sem nada absorver. É desta sucção que trata o livro de Havelock Ellis em que Freud encontrou o conceito de auto-erotismo.

"Tomamos como modelo das manifestações sexuais infantis a sucção (sucção voluptuosa)”, escreve Freud (1905), e mais longe: “A sucção, que já aparece no recém-nascido e que pode prolongar-se até a maturidade ou manter-se durante toda a vida, consiste numa repetição rítmica com a boca (os lábios) de um contato de sucção, cuja finalidade alimentar está excluída" (1905, p.102).

Freud irá enunciar então que, no auto-erotismo, o objeto pode se confundir com a fonte, isto é, a zona erógena; na suç̧ão, os lábios. O passo seguinte consiste, para Freud, em separar o auto-erotismo do objeto, e ele se torna, então, anobjetal, inato e não depende mais de nenhum Outro da experiência primordial. Qualquer historicidade estará, assim, excluída.

Uma tal concepção de um auto-erotismo inato opõe-se radicalmente àquilo que está apresentado no Esquisse ${ }^{13}$. Mas esta possibilita a Freud conceber um aparelho psíquico que não seria mais, então, totalmente tributário da experiência da satisfação da necessidade. Ele emancipa assim o psicológico do fisiológico e abre, pela mesma via, a possibilidade de um campo da pulsão independente do campo da autoconservação.

Entretanto, existe uma contradição, in adjeto, em pensar-se um auto-erotismo inato. Primeiramente, porque Eros, na mitologia grega, está sempre do lado do sexual, isto é, da intervenção de um outro para que isso possa acontecer. Eros vem se opor a todos os mitos autogeradores, de reprodução por cissiparidade. Nada é possível sem o outro.

Além disso, há a própria maneira com que o auto-erotismo aparece no livro de Havelock Ellis sobre a sucção. Esse livro trata de sexualidade, e de sexualidade nos adultos. Nessa sucção, é o aspecto masturbatório que interessa ao autor, que o excita, poderíamos dizer, pois é um livro excitante. No início do século, esses senhores de colarinho duro, gravata e monóculo devoravam tratados e monografias sobre a sexualidade solitária. Mas, ainda que ela fosse solitária, isso não significa que ela não fosse sustentada por fantasmas implicando o outro. Só que, aí está, Freud ainda não havia construído a teoria do fantasma. 
Portanto, eis aí o pano de fundo sobre o qual Freud irá afirmar a existência de uma sexualidade infantil, desde o nascimento. Como $\mathrm{H}$. Ellis, ele vai considerar a sucção como sexual. Pelo fato de não derivar da experiência de satisfação da necessidade, ele vai considerá-la inata, isto é, independente da relação com um Outro.

Levando às últimas conseqüências esse movimento do pensamento de Freud, certos autores serão conduzidos a dar o seguinte passo: conceber. um auto-erotismo sem Eros, isto é, um primeiro tempo autista em todo bebê. M. Mahler afirmará isso e será seguida, num primeiro tempo, por $\mathrm{F}$. Tustin ${ }^{14}$. É preciso observar aqui que foi dialogando com seu amigo $C$. Trevarthen - justamente um dos fundadores da psicolingüística - que $F$. Tustin disse ter compreendido que essa hipótese seria insustentável.

Ainda que Freud não tenha jamais chegado a um extremo semelhante, ele devia sentir que sua hipótese sobre um auto-erotismo inato não era segura, e compreende-se que ele tenha se ligado ainda mais à teoria do apoio para fazer frente a esse movimento em sua obra. Em "Três ensaios para uma teoria da sexualidade" as observações sobre o apoio são freqüentemente acréscimos de 1915, o que é coerente com o que Freud elabora, no mesmo ano, em seu texto "Pulsões e seus destinos". Ele apresenta aí seu conceito de pulsão, dizendo que haverá modificações. Seria essa pulsão o representante psíquico das excitações vindas do interior do corpo? Compreendemos então que ele dê o exemplo da fome e da sede. Lacan (1964) terá a audácia de mostrar que aí estão tergiversações, mas o fio que leva Freud a forjar esse conceito é o outro. "Não se trata do organismo em sua totalidade. E o vivo que está interessado? Não", enuncia ele, e acrescenta mais adiante: "A constância do crescimento próibe qualquer assimilação da pulsão a uma função biológica, a qual sempre tem um ritmo. A pulsão não tem subida nem descida, é uma força constante" (p.150). A fonte é a zona erógena que, no recém-nascido, é, por excelência, a boca. Mas não podemos seguir Freud quando, a respeito da sucção, toma esta zona como objeto. Ele o faz para tentar pensar outra coisa além do objeto de satisfação da necessidade, no que ele tem razão. Relendo Freud, Lacan observa que: "Nenhum objeto da necessidade pode satisfazer a pulsão. A boca que se abre no registro da pulsão não se satisfaz com alimento"15. Imediatamente, à lista habitual de Freud (seios, nádegas), ele acrescenta então o olhar e a voz. Estes dois últimos objetos - que não são os da satisfação de uma necessidade qualquer - são centrais na clínica do recémnascido. Quanto ao seio, este permanece marcado por seu valor de objeto da satisfação da necessidade alimentar, e vimos, no caso de Marianne, o quanto a satisfação da pulsão oral está num outro registro.

Lacan irá manter o termo pulsão apenas para as pulsões sexuais parciais e porá tudo o que se refere à conservação do indivíduo num registro diferente. Todo o registro da necessidade sai, dessa forma, do campo pulsional ${ }^{16}$.

O crescimento, a fonte e o objeto são os três primeiros componentes 
da pulsão. É preciso acrescenter um quarto, o objetivo de atingir a satisfação pulsional que consiste na montagem de um circuito pulsional em três tempos. Trata-se, para a pulsão, de realizar um certo percurso. É este percurso que traz a satisfação pulsional, radicalmente separada de qualquer satisfação de necessidade orgânica. Este trajeto, em forma de circuito, vem se fechar em seu ponto de partida. A partir daí, para a pulsão não se trata mais de ir na direção de um objeto da necessidade $\mathrm{e}$ de satisfazer-se, mas sim de encontrar um objeto que a crie, isto é, que permita a ela percorrer todos os tempos necessários para seu fechamento, inúmeras vezes.

O primeiro é ativo, o recémnascido (no caso que nos interessa) vai na direção de um objeto externo - o seio, ou a mamadeira. O segundo é reflexivo, tomando como objeto uma parte do próprio corpo - a chupeta ou o dedo; é aí que Freud situa a sucção ${ }^{17}$. O terceiro tempo da pulsão é quando o recém-nascido faz a si mesmo objeto de um outro, este conhecido novo sujeito - a mãe, por exemplo. Freud qualifica-o de "passivo". O bebê não é passivo na situação, ele a suscita, com toda a evidência. É ele que procura ser olhado, ser ouvido ou então, no nível oral, "oferecer o pezinho para comer". Este aspecto do terceiro tempo do circuito pulsional, eminentemente ativo, já havia sido observado por Lacan, que o chamou de tempo do "fazer-se". Recentemente vimos um bebê que, colocado nu sobre seu trocador, agita-se, oferece a si mesmo como objeto na antecipa- ção da voluptuosidade oral materna. Ele dá seu dedo para morder e espia, então, atento. A alegria inscrevese no rosto e no olhar de sua mãe, para quem ele é "bom de morder". É justamente este gozo que ele vem ligar a ela. Ainda é preciso que a mãe, saboreando este gozo, saiba rapidamente privar-se dele dizendo a seu bebê que não deve excitar-se tanto e que papai - ou qualquer outro terceiro que vier à cabeça da mãe não estaria de acordo. Por meio desta privação de gozo que a mãe se impõe, ela significa a seu bebê que ela mesma está submetida à lei, marcada pela castração, pela falta.

Quando esse terceiro tempo acontece, ele garante que, no pólo alucinatório de satisfação do desejo haverá traços mnêmicos deste Outro materno, deste próximo assegurador. Mas, mais precisamente, traços mnêmicos de seu gozo; deste momento em que a mãe sorri de prazer para esse bebê que se faz olhar ou que oferece seu pé para morder. Temos certeza então de que, em seguida, quando ele estiver sozinho, sugando seu polegar ou chupeta, haverá reinvestimento dos traços mnêmicos deste Outro materno. Freud, no "Projeto", chama-os de representações do desejo (Wunschvorstellungen). Como ele fala do recém-nascido, só pode se tratar do desejo de seu Outro Primordial, seu próximo assegurador, como ele o chama. Nesse caso, estamos certos de que auto-erotismo contém Eros. Sem Eros, auto-erotismo se escreve autismo.

De fato, esse terceiro tempo do circuito pulsional, esse momento em que ele vai se fazer objeto de um 
novo sujeito, o autista não o conhece. Para ele o circuito pulsional não se fecha. De imediato não existe a possibilidade de nenhum tempo propriamente auto-erótico, porque nada de um prazer suscitado no Outro pode ser registrado no pólo alucinatório de satisfação. Esta necessidade de pensar primeiro no terceiro tempo do circuito pulsional antes de poder afirmar a natureza auto-erótica do segundo é tão central, que $\mathrm{D}$. Widlöcher propõe claramente inverter a ordem, isto é, põe o auto-erotismo no terceiro tempo.

Voltemos agora à questão do objeto para situar o modo com que a voz poderia ser o primeiro objeto da pulsão oral.

Fernald (1982, pp.104-13), um dos fundadores da psicolingüística, constatava nos recém-nascidos uma apetência oral exacerbada para uma forma particular de palavra materna, que foi chamada de "motherease" ("mamanhês"). Este motherease apresenta uma série de características específicas de gramática, de pontuação, de escanção, e uma prosódia especial. $\mathrm{O}$ autor interessou-se pelas características prosódicas do motherease e sobre o efeito que este produz na apetência do recém-nascido. Trabalhando com bebês de 1 a 3 dias de vida, o que descobriu ele? Que antes mesmo da descida do leite, um recém-nascido que portanto ainda não teve a experiência da satisfação alimentar, ouvindo uma forma prosódica particular da voz de sua mãe dirigida a ele, torna-se muito atento e começa a sugar intensamente uma chupeta não nutriti$\mathrm{va}^{18}$. O recém-nascido chupa decidido ouvindo a prosódia desse "mamanhês", até mesmo quando se trata de uma gravação. Entretanto, Fernald descobriu que se ele grava a palavra da mãe falando a seu bebê, sem a presença do mesmo, o resultado obtido é diferente. Não se encontram mais os mesmos picos prosódicos e o bebê demonstra então menos interesse. $\mathrm{E}$, se uma mãe se dirige a um outro adulto, os picos prosódicos se tornam ainda mais fracos e a apetência do bebê se anula.

Fernald tentou descobrir se havia uma situação em que um adulto, falando com outro adulto, produzisse esses mesmos picos prosódicos específicos do motherease ("mamanhês"). Esta situação existe, mas para obter esses picos é preciso uma situação que some, o que é raro, estupefação, surpresa e, ao mesmo tempo, grande prazer, alegria. Portanto, estupefação e prazer conjugados produzem esse tipo de pico prosódico. Fernald nada conclui.

Enquanto psicanalistas, como ler esses dados?

Observemos, primeiramente, a diferença radical entre o objeto causa de desejo - o da pulsão - e o objeto de satisfação da necessidade, que não está presente aqui.

Freud em $O$ chiste e suas relações com o inconsciente descreve o que chama de papel da terceira pessoa. $\mathrm{Na}$ prática analítica com 
crianças autistas observamos que o terceiro tempo do circuito pulsional, o momento em que o gozo do $\mathrm{Ou}$ tro (e do outro) está "enganchado" corresponde ao papel desta terceira pessoa. Aquela que, ouvindo "uma formação de palavra defeituosa como uma coisa ininteligível, incompreensível, enigmática”, longe de rejeitá-la como não pertencendo ao código, após um tempo de estupefação deixase levar pela iluminação e reconhece aí um chiste. Aceitar deixar-se confundir, estupefazer é a marca da falta no Outro. Este Outro não está então não iniciado, tem uma falta. E o segundo momento é o do riso. Toda a segunda parte do livro de Freud é sobre esse riso, que é prazer, gozo ${ }^{19}$. Com a estupefação e o riso do $\mathrm{Ou}$ tro barrado, estamos no terceiro tempo do circuito pulsional. Estupefação e alegria são também as características da prosódia do motherease ("mamanhês") de que o recém-nascido é tão ávido. $O$ que nos ensina a pesquisa de Fernald? Esta nos diz que desde o nascimento, e antes de qualquer experiência de satisfação alimentar, o recém-nascido tem uma apetência extraordinária para o gozo que a visão de sua presença desencadeia no Outro materno.

Os bebês que se tornaram autistas nos levam a pensar que o recémnascido só olharia para sua mãe - ou o Outro Primordial de sua vida quando ele fizesse a experiência desta prosódia na voz materna. Esta prosódia lhe possibilitaria identificar sua presença como o objeto causa de um gozo deste Outro Primordial. Ele vai procurar o rosto que corresponde a esta voz particular. E ele procurará 
também fazer-se objeto deste olhar, no qual ele lerá que ele é o objeto causa dessa surpresa e dessa alegria que a prosódia da voz e os traços do rosto materno refletem. Ele terá então amarrado com ela um circuito pulsional escópico.

Observemos que as pesquisas dos psicolingüistas fazem-se fora do contexto de qualquer apoio sobre a satisfação das necessidades vitais. E sobretudo aí que a pulsão invocante parece irresistível; isto é, quando ela é apenas pulsão. Isto justifica o fato de termos retomado seriamente a teoria do apoio.

Parece-me que com o objeto voz - ou mais precisamente com a prosódia particular da voz materna - Freud teria podido sair do impasse em que se encontrou entre um apoio muito ancorado na fisiologia e um auto-erotismo inato, isto é, excluindo o Outro. Talvez ele tivesse tido a idéia ouvindo o poema de Heinrich Schütz:

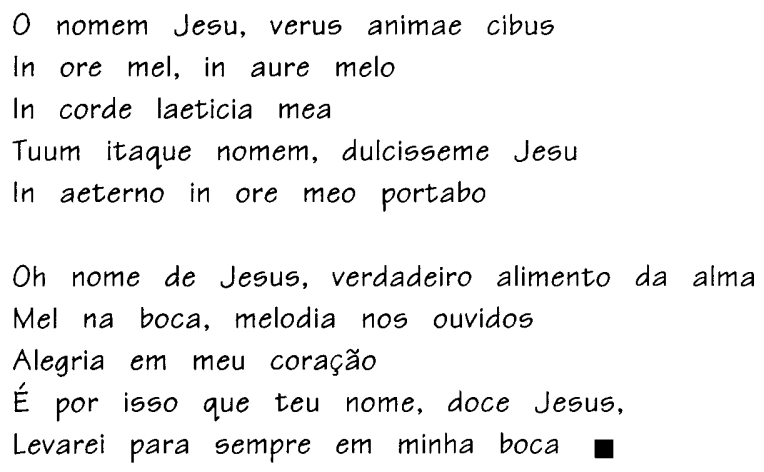

\section{REFERENCIAS BIBLIOGRÁFICAS}

Bardies, B. de B. (1996). Comment le langage vient aux enfants. Paris: Odile Jacob.

Ellis, H. La pudeur, la périodicité sexuelle, l'auto-érotisme, l'inversion sexuelle. In Cercle du Livre Prècieux.

Fernald, A. \& Simon, T. (1982). Expanded intonation contours in mother's speach to newborns. In Developmental Psychology, 20 (1), p. 104-13.

Freud, S. (1895). L'esquisse d'une psychologie scientifique. In La naissance de la psychanalyse. Paris: PUF, 1973.

(1905). Trois essais sur une théorie de la sexualité (Phillippe Koepel, trad.). Gall.

(1905). Le mot d'esprit et ses rapports avec l'inconscient.

(1938). Abrégé de psychologie. 
Lacan, J. (1964). Séminaire, Livre XI, Les quatre concepts fondamentaux de la psychanalyse. Paris: Seuil.

Laznik-Penot, M.-C. (1995). Les effets de la parole sur le regard des parents, fondateur du corps de l'enfant. Ind Les parents, le pédiatre et le psychanalyste (Danièle Brun, ed.). Condé-sur-l'Escaut: Editions P.A.U.

Mercier, A. (1995). "Oralité: questions à propos de nourrissons en nutrition artificielle”. Mémoire de Maîtrise. Universidade de Paris VII-Diderot, Paris.

Mehler, J. \& Dupoux, E. (1990). Naître humain. Paris: Odile Jacob.

Raimbault, G. (1980). Les nourritures terrestres, à propos d'enfants en réanimation digestive. In Psychiatrie de l'Enfant, Vol. XXIII, 1, p.5-84.

Spitz (1962). Le oui et le non: la genèse de la communication humaine. Paris: PUF.

\section{NOTAS}

1 Único texto em que Freud (1973) aborda longamente o papel do outro assegurador na constituição do aparelho psíquico do bebê.

2 O que significa que poderia haver outros níveis além do visual.

3 Talvez ousar emancipar a experiência de satisfação pulsional da experiência de satisfação da necessidade fosse um passo de ruptura com Freud que ele nunca deu.

4 B. de Boisson Bardies conta também que os bebês submetidos à escuta de um poema durante os últimos meses da vida fetal diferenciam esse poema. Eles o preferem a um outro, não ouvido, ainda que seja a voz de sua mãe que o lê. Eles preferem o poema que eles conhecem, ainda que seja uma voz feminina desconhecida que o lê. Eles são até mesmo capazes, sugando de modo particular, de optar pela fita do poema conhecido em detrimento daquela com a voz da mãe. Vemos portanto que, desde o nascimento, a voz da mãe não é o único determinante acústico em jogo, mas também algumas caraterísticas das cadeias significantes previamente ouvidas. Veremos que a prosódia também tem, de imediato, um papel preponderante.

5 Trata-se de uma "laparoschisis" grave que necessitou de seis meses de internação e de algumas intervenções cirúrgicas

6 Situação que ainda persistia no momento em que esta apresentação foi feita, tendo Marianne 14 meses. Foi apenas a partir de 28 meses que ela pode se alimentar exclusivamente pela boca.

7 Esse hospital está equipado para que os pais possam estar com os bebês desde o início. Entretanto, há progressos a fazer; graças à sua experiência pessoal e à sua profissão, os pais de Marianne esperam poder melhorar o tipo de acolhida nesse tipo de espaço hospitalar, para que a relação do bebê com seus pais seja mais bem favorecida. 
8 Talvez com receio de pôr o próprio Freud em perigo repropondo a teoria do apoio sobre a satisfação da necessidade.

9 Ainda mais que a pesquisa de G. Raimbault foi encomendada pelo INSERM.

10 No último parágrafo A. Mercier (1995) faz alusão às outras competências dos recém-nascidos e cita o livro Nascer humano, de Mehler e Dupoux (1990), primeiro livro a divulgar em francês os trabalhos de pesquisa dos psicolingïistas sobre os recém-nascidos, obra sobre a qual já fizemos referência.

11 Que Freud chama Wunschvorstellungen, representações de desejo.

12 Esta é mantida por Laplanche e Pontalis em seu Dicionário e conta com a aprovação da maioria dos autores psicanalistas franceses.

13 Mesmo que o termo "auto-erotismo" não tenha aparecido ainda - pois é apenas em 1905 que Freud o emprega -, é evidente que a própria noção de pólo alucinatório de satisfação, que supõe a revivescência de traços mnêmicos ligados a traços do Outro inesquecível, implica qualquer outra concepção do auto-erotismo.

14 Se esse passo foi dado por autores anglo-saxões, e não por autores da escola francesa, é porque esta permaneceu muito ligada à idéia de uma historicidade.

15 O próprio Lacan não teve tempo de tirar conclusões dessa asserção, que implica uma revisão completa da teoria do apoio.

16 A pulsão não é mais um conceito charneira entre o biológico e o psíquico, mas um conceito que articula o significante e o corpo, o que não é o organismo.

17 Mas iremos ver que é apenas depois do terceiro tempo que poderemos dizer se há ou não auto-erotismo.

18 Este detalhe é importante se quisermos distinguir os objetos da satisfação $\mathrm{da}$ necessidade dos objetos pulsionais propriamente ditos.

19 Não se trata aqui de prazer no sentido do princípio de prazer, que é sobretudo um princípio de não desprazer. 